\title{
Deposição de sílica e teor de nitrogênio e silício em arroz
}

\section{Silica deposition and rate the nitrogen is silicon in rice}

\author{
Munir Mauad ${ }^{1 *}$; Carlos Alexandre Costa, Crusciol²; \\ Hélio Grassi Filho ${ }^{3}$; Silvia Rodrigues Machado ${ }^{4}$
}

\section{Resumo}

A adubação nitrogenada é pratica importante para alcançar altas produtividades, entretanto doses elevadas de nitrogênio podem causar tombamento e tornar as plantas mais suscetíveis a doenças. Numerosos estudos têm demonstrado que muitas gramíneas acumulam silício em seus tecidos, e que a maior parte deste elemento é depositado na folha, o que funcionária como uma barreira mecânica a entrada de doenças. Entretanto elevadas doses de nitrogênio podem diminuir a deposição de sílica nas plantas. $\mathrm{O}$ objetivo deste trabalho foi avaliar o teor de nitrogênio e silício na parte aérea, e a deposição de sílica em folhas de plantas de arroz de terras altas em função das doses de Si e N. O delineamento experimental utilizado foi inteiramente casualizado, em esquema fatorial $3 \times 2$, com cinco repetições. Os tratamentos foram constituídos por três doses de $\mathrm{N}\left(5,75\right.$ e $\left.150 \mathrm{mg} \mathrm{dm}^{-3} \mathrm{de} \mathrm{N}\right)$ tendo como fonte a uréia e duas doses de $\mathrm{Si}\left(0\right.$ e $400 \mathrm{mg} \mathrm{dm}^{-3} \mathrm{de} \mathrm{SiO}_{2}$ ) tendo como fonte o silicato de cálcio (Wollastonita). O incremento da adubação com uréia reduziu o teor de Si na planta de arroz e a deposição de sílica na parede externa das células da epiderme das folhas de arroz.

Palavras-chave: Oryza sativa, adubação e anatomia vegetal

\begin{abstract}
The nitrogen fertilization is an important practice to reach high productivity, however, nitrogen high level can cause lodging and make the plants more sensitive to disease. Numerous studies has demonstrate that a lot of grasses accumulate silicon at its tissues, and the biggest part of this element is deposited on the leaf, that would work like a mechanical barrier to diseases come in. However, high levels of nitrogen can reduce the silica deposition at the plants. The objective of this study was to evaluate silicon and nitrogen content in shoot and silica deposition in upland rice leaf as a result of $\mathrm{Si}$ and $\mathrm{N}$ levels. The experimental design used was completely randomized in factorial schema $3 \times 2$ with five replications. The treatments consisted from levels of $\mathrm{N}\left(5,75\right.$ and $150 \mathrm{mg} \mathrm{dm}^{-3}$ of soil) in urea form and two levels of $\mathrm{SiO}_{2}\left(0\right.$ e $\left.400 \mathrm{mg} \mathrm{dm}^{-3}\right)$ in calcium silicate form (Wollastonita). The increased of urea fertilization reduced the silicon content of rice plants and the silica deposition at the external cells wall the epidermal rice leafs.
\end{abstract}

Key words: Oryza sativa, fertilization, vegetation anatomy

\footnotetext{
${ }^{1}$ Prof. Dr. da Universidade Federal da Grande Dourados, Faculdade de Ciências Agrárias, UFGD, Dourados, MS. E-mail: munirmauad@ufgd.edu.br

${ }^{2}$ Prof. Dr. do Dept ${ }^{\circ}$ de Produção Vegetal, Universidade Estadual Paulista, Faculdade de Ciências Agronômicas, UNESP, Botucatu, SP. E-mail: crusciol@fca.unesp.br

${ }^{3}$ Prof. Dr. do Dept ${ }^{\circ}$ de Ciências Ambientais, UNESP, Botucatu, SP. E-mail: heliograssi@fca.unesp.br

${ }^{4}$ Prof $^{\mathrm{a}}$. Dr ${ }^{\mathrm{a}}$. do Dept ${ }^{\mathrm{o}}$ de Botânica, UNESP, Instituto de Biociências, Botucatu, SP. E-mail: smachado@ibb.unesp.br

* Autor para correspondência
} 


\section{Introdução}

Embora não faça parte do grupo de elementos essenciais para as plantas, relatos na literatura têm demonstrado o efeito benéfico do silício em várias espécies, como no arroz (MAUAD; CRUSCIOL; GRASSI FILHO, 2011), na cana-de-açúcar (SOUZA; KORNDÖRFER; WANGEN, 2010) e em gramíneas forrageiras (SÁVIO et al., 2011).

Dentre os efeitos benéficos do silício em plantas acumuladoras deste elemento, pode-se destacar a redução da intensidade de inúmeras doenças de importância econômica (DATNOFF; RODRIGUES; SEEBOLD, 2007), que pode ocorrer por meio de barreira química como a produção de fenóis pelas plantas (RODRIGUES et al., 2003) ou por meio de barreira física como o aumento da espessura da parede celular em conseqüência da deposição de sílica nas células dos tecidos da epiderme (AGARIE et al., 1998a).

O acúmulo de sílica em gramíneas é um fenômeno bem conhecido, porém o mecanismo de deposição desta sílica não é muito claro. Segundo He et al. (2005) a proteína SBP117 pode estar associada a deposição de sílica em gramíneas, devido a distribuição desta proteína estar localizada nos locais de acúmulo de sílica como as células da epiderme das folhas.

A sílica amorfa $\mathrm{SiO}_{2} \cdot \mathrm{nH}_{2} \mathrm{O}$ é depositada nos tecidos das plantas superiores após o ácido monossilícico ${ }_{4} \mathrm{SiO}_{4}$ ser absorvido e a água ser perdida por transpiração (SANGSTER; HODSON; TUBB, 2001). Em arroz, a maior parte do $\mathrm{Si}$ absorvido pela planta é depositada na folha, nos tecidos da epiderme logo abaixo da cutícula, mais precisamente nas paredes celulares mais externas formando uma dupla camada de sílica-celulose, conferindo resistência à penetração de hifas, diminuindo a permeabilidade ao vapor de água e com isso limitando a perda de água através da cutícula (YOSHIDA; OHNISHI; KITAGISHI, 1962; AGARIE et al., 1998b). O Si é também depositado nas células buliformes, nos colmos, na superfície das folhas e das cascas (RAVEN, 2003), em idioblastos especializados (células de sílica) e nos pêlos (tricomas) (MOTOMURA; FUJII; SUZUKI, 2001).

A deposição de sílica geralmente não ocorre em órgãos juvenis durante o estágio de expansão celular, exceto em células especializadas as quais podem ser silificadas mesmo em folhas juvenis ainda não diferenciadas. Em órgãos maduros, no entanto, a deposição de sílica pode ocorrer em células de tecidos associados com proteção, armazenamento, suporte e sustenção. Essa deposição é influenciada pela idade, tipo e localização do tecido e por fatores do solo como teor de silício, teor de nutriente, teor de água, $\mathrm{pH}$ e tipo de solo (SANGSTER; HODSON; TUBB, 2001).

Dentre as praticas de manejo cultural, a adubação nitrogenada pode alterar a disponibilidade e a deposição de Si para as plantas, pois segundo Wallace (1989), o nitrogênio (N) diminuiu a concentração de silício nas plantas, sendo a fonte amoniacal mais prejudicial que a nítrica para a absorção de Si. Uma possível explicação para isto, está no fato da adubação nitrogenada ser uma das praticas de manejo que produz as maiores alterações no $\mathrm{pH}$ do solo (BARBOSA FILHO; FAGERIA; SILVA, 2005) e da $\mathrm{pH}$ rizosfera (SOUSA; MIRANDA; OLIVEIRA, 2007).

As formas de Si disponível no solo dependem diretamente da sua concentração na solução do solo e do $\mathrm{pH}$ do solo, sendo que quanto mais alcalino, maior o grau de ionização do $\mathrm{H}_{4} \mathrm{SiO}_{4}$ (ILER, 1979) Oliveira, Korndorfer e Pereira (2007) relacionaram o maior teor de Si em plantas de arroz, a maior disponibilidade de Si no solo, em função do aumento do $\mathrm{pH}$ do solo. Tamai e Ma (2003) encontram valores de silício na solução solo de $0,6 \mathrm{mM}$ e 0,35 $\mathrm{mM}$, em solo alcalinos e ácidos respectivamente.

Quando a absorção de cátions é maior que a de ânions, a solubilidade do Si é diminuída, entretanto quando a absorção de ânions é maior que a de cátions a solubilidade do silício é aumentada (WALLACE, 
1992). Isto pode estar relacionado à manutenção do equilíbrio eletroquímico, pois dificilmente as plantas absorvem quantidades equivalentes de cátions e ânions (SOUSA; MIRANDA; OLIVEIRA, 2007), o que resulta em alteração do $\mathrm{pH}$ do solo e da rizosfera, influenciando a disponibilidade de silício para as plantas.

O objetivo deste trabalho foi avaliar o teor de nitrogênio e silício na parte aérea, e a deposição de sílica em folhas de plantas de arroz de terras altas em função das doses de Si e N.

\section{Material e Métodos}

O experimento foi instalado e conduzido em túnel plástico no período de 30/11/99 a 25/03/00, em área experimental pertencente ao Departamento de Produção Vegetal da Faculdade de Ciências Agronômicas - UNESP - Campus de Botucatu. O solo utilizado no experimento foi classificado como Latossolo Vermelho distrófico (EMBRAPA, 1999) e a análise química, realizada segundo métodos propostos por Raij e Quaggio (1983), apresentou os seguintes resultados: $\mathrm{P}=1 \mathrm{mg} \mathrm{dm}{ }^{-3} ; \mathrm{M} . \mathrm{O}=16$ $\mathrm{g} \mathrm{dm}^{-3}, \mathrm{pH}=4,0 ; \mathrm{H}+\mathrm{Al}=64,4 \mathrm{mmol}_{\mathrm{c}} \mathrm{dm}^{-3} ; \mathrm{K}^{+}=$ $0,14 \mathrm{mmol}_{\mathrm{c}} \mathrm{dm}^{-3} ; \mathrm{Ca}^{2+}=2,3 \mathrm{mmol}_{\mathrm{c}} \mathrm{dm}^{-3} ; \mathrm{Mg}^{2+}=0,5$ $\mathrm{mmol}_{\mathrm{c}} \mathrm{dm}^{-3}, \mathrm{Al}^{+3}=4 \mathrm{mmol}_{\mathrm{c}} \mathrm{dm}^{-3}$ e $\mathrm{V}=4,36 \%$. A calagem foi realizada 60 dias antes da semeadura de modo a elevar o valor V para 50 \% (RAIJ et al., 1996), utilizando-se calcário dolomítico com PRNT de $85 \%$.

Adotou-se o delineamento experimental inteiramente casualizado, com esquema fatorial 3 x 2, com cinco repetições, totalizando 30 unidades experimentais. Cada unidade experimental foi constituída por vaso com dimensões internas de 40 x 40 × $25 \mathrm{~cm}$, com $30 \mathrm{~kg}$ de solo e 2 linhas de semeadura de 0,40 m de comprimento e espaçadas de $0,20 \mathrm{~m}$ entre si. A cultivar de arroz utilizado foi IAC-202.

Os tratamentos constituíram da aplicação de 5, 75 e $150 \mathrm{mg} \mathrm{kg}^{-1}$ de $\mathrm{N}$ no solo, utilizando uréia

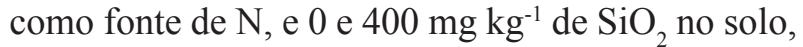
o equivalente a 0 e $187 \mathrm{mg} \mathrm{kg}^{-1} \mathrm{de}$ Si. Utilizou-se, como fonte de $\mathrm{Si}$, silicato de cálcio (Wollastonita), com as seguintes características químicas: total de óxido de silício $\left(\mathrm{SiO}_{2}\right)=452 \mathrm{~g} \mathrm{~kg}^{-1}$; óxido de silício $\left(\mathrm{SiO}_{2}\right)$ solúvel em ácido cítrico a $2 \mathrm{dag} \mathrm{L}^{-1}=318 \mathrm{~g}$ $\mathrm{kg}^{-1}$.

A semeadura foi realizada no dia 30/11/99, utilizando 70 sementes viáveis por linha de semeadura. Aos seis dias após a semeadura, quando 50 \% das plântulas de cada unidade experimental apresentavam o coleóptilo acima do nível do solo, considerou-se a data de emergência. Realizou-se um desbaste aos nove dias após a emergência, de modo a manter 30 plantas por linha de semeadura.

$\mathrm{Na}$ adubação de semeadura foi aplicado: $5 \mathrm{mg}$ $\mathrm{kg}^{-1}$ de $\mathrm{N}, 100 \mathrm{mg} \mathrm{kg}^{-1}$ de $\mathrm{P}$ e $150 \mathrm{mg} \mathrm{kg}^{-1}$ de $\mathrm{K}$, utilizando-se uréia (440 $\mathrm{g} \mathrm{dm}^{-3}$ de $\mathrm{N}$ ), superfosfato simples $\left(180 \mathrm{~g} \mathrm{~kg}^{-1}\right.$ de $\left.\mathrm{P}_{2} \mathrm{O}_{5}\right)$ e cloreto de potássio (600 $\mathrm{g} \mathrm{kg}^{-1}$ de $\mathrm{K}_{2} \mathrm{O}$ ) respectivamente. Aos 35 dias após a emergência foi realizada adubação de cobertura com nitrogênio, utilizando 70 e $145 \mathrm{mg}$ $\mathrm{kg}^{-1}$ de $\mathrm{N}$, de forma que o experimento ficasse com três diferentes doses de $\mathrm{N}$, sendo $\mathrm{N}_{1}=5 \mathrm{mg} \mathrm{kg}^{-1}$ de $\mathrm{N}, \mathrm{N}_{2}=75 \mathrm{mg} \mathrm{kg}^{-1}$ de $\mathrm{N}$ e $\mathrm{N}_{3}=150 \mathrm{mg} \mathrm{kg}^{-1}$ de N. O Si foi incorporado ao solo 30 dias antes da semeadura, seguindo recomendação de Korndörfer et al. (1999a).

Foram coletadas 50 folhas bandeiras ao acaso de cada unidade experimental no período do florescimento, quando $50 \%$ das panículas estavam visíveis (RAIJ et al., 1996). O material coletado foi seco em estufa a $60{ }^{\circ} \mathrm{C}$, até atingir peso constante, e posteriormente moído. Na matéria seca das folhas foi determinado o teor de N, segundo Malavolta, Vitti e Oliveira (1997). O teor de Si no solo e na planta (colmo + folha) foi determinado no final do experimento (109 DAE), segundo método proposto por Korndörfer, Pereira e Nolla (2004).

Para análise da estrutura anatômica do limbo foliar foram coletadas cinco folhas bandeira ao acaso de cada tratamento na época do florescimento. 
As folhas foram separadas do colmo na altura da lígula, seccionando o limbo foliar (lamina foliar) da bainha foliar. Amostras da região mediana do limbo foliar de cada folha foram fixadas em solução de Karnowsky por 24 horas, seguida de desidratação em série alcoólica e infiltradas em resina glicolmetacrilato (CARMELLO-GUERREIRO, 1995). Os blocos foram seccionados em micrótomo rotatório manual Leica RM 2145, e os cortes com espessura de $8 \mu \mathrm{m}$ foram corados com azul de toluidina $\mathrm{pH}$ 3,6 a 0,05\% (FEDER; O'BRIEN, 1968). As amostras foram montadas em "Entellan". Os aspectos mais relevantes foram fotografados em fotomicroscopio Zeissm filme T MAX, ASA 100.

Os resultados obtidos para o teor de $\mathrm{N}$ e Si na planta foram submetidos à analise de variância, e as médias dos tratamentos foram comparadas pelo Teste de Tukey a 5\%, enquanto para o estudo anatômico foi feita realizada descrição visual como utilizado neste tipo de estudo.

\section{Resultados e Discussão}

Pela análise de variância e baseados nos valores de F (Tabela 1), detectou-se efeito significativo e isolado de dose de nitrogênio para teor de nitrogênio e interação doses de nitrogênio x doses de silício para o teor de silício.

Tabela 1. Valores de F, e suas respectivas significâncias, obtidas da analise de variação para teor de nitrogênio na folha bandeira e silício na parte aérea de arroz de terras altas em função das doses de nitrogênio e silício.

\begin{tabular}{ccc}
\hline Tratamento & $\mathrm{N}$ & $\mathrm{Si}$ \\
\hline Doses de N & $42,21^{* *}$ & $131,3^{* *}$ \\
Doses de Si & $0,29^{\text {ns }}$ & $72,2^{* *}$ \\
N x SI & $1,66^{\text {ns }}$ & $6,9^{* *}$ \\
C.V $(\%)$ & 6,7 & 18,3 \\
\hline
\end{tabular}

**,**, * e ns significativo a $1 \%$ e $5 \%$ - não significativo

Fonte: Elaboração dos autores.
Observa-se aumento do teor de $\mathrm{N}$ a medida que as doses do elemento foram incrementados (Tabela 2), estando os valores, dentro da faixa adequada para a cultura que é de 27 a $35 \mathrm{~g} \mathrm{~kg}^{-1}$ segundo Raij et al. (1996).

Tabela 2. Produção de massa seca, teor de macronutrientes na folha bandeira e silício (colmo + folha) em função de cultivares, tensão de água no solo e doses de silício.

\begin{tabular}{cc}
\hline Tratamento & $\mathrm{N}$ \\
\hline Doses de $\mathrm{N}\left(\mathrm{mg} \mathrm{kg}^{-1}\right)$ & $\mathrm{g} \mathrm{kg}^{-1}$ \\
5 & $27,6 \mathrm{c}$ \\
75 & $30,0 \mathrm{~b}$ \\
150 & $33,5 \mathrm{a}$ \\
\hline
\end{tabular}

Médias seguidas de letras iguais não diferem entre si pelo teste de Tukey, $5 \%$. Teste $\mathrm{F}-\mathrm{ns}$, *, ** - não significativa e significativos a 5 e $1 \%$.

Fonte: Elaboração dos autores.

Para o teor de Si na planta houve interação significativa entre doses de $\mathrm{N}$ e $\mathrm{Si}$, estando o desdobramento apresentado na Tabela 3. Analisando os efeitos de doses Si dentro das doses de N, verificase efeito significativo de $\mathrm{Si}$ para todas as doses de N. Para todas as doses de N, a aplicação de Si aumentou significativamente o teor do nutriente na planta. Quando a adubação nitrogenada foi menor, o teor de Si na planta teve aumento mais pronunciado comparados com as doses mais elevadas de N. Analisando o desdobramento dos efeitos de doses de $\mathrm{N}$ dentro da dose de $\mathrm{Si}$, observou efeito significativo de $\mathrm{N}$ na adubação silicatada, onde a não aplicação de $\mathrm{N}$ em cobertura diferiu significativamente da aplicação, independentemente da adição de $\mathrm{Si}$ ao solo. Observa-se que a aplicação das doses 75 e 150 $\mathrm{mg} \mathrm{dm}{ }^{-3}$ de $\mathrm{N}$ propiciaram diminuição dos teores de Si na planta. 


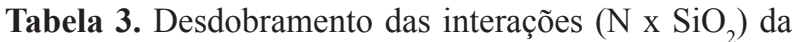
análise de variância referente ao teor de silício na planta de arroz.

\begin{tabular}{ccc}
\hline \multirow{2}{*}{ Doses de $\mathrm{N}$} & \multicolumn{2}{c}{ Doses de $\mathrm{SiO}_{2}$} \\
\cline { 2 - 3 } & 0 & 400 \\
\hline$\left(\mathrm{mg} \mathrm{kg}^{-1}\right)$ & $---------\mathrm{mg} \mathrm{kg}^{-1}-----------$ \\
5 & $12,2 \mathrm{a} \mathrm{B}$ & $29,9 \mathrm{a} \mathrm{A}$ \\
75 & $6,2 \mathrm{~b} \mathrm{~B}$ & $14,6 \mathrm{~b} \mathrm{~A}$ \\
150 & $6,8 \mathrm{~b} \mathrm{~B}$ & $13,5 \mathrm{~b} \mathrm{~A}$ \\
\hline
\end{tabular}

Médias seguidas das mesmas letras, minúscula na vertical e maiúscula na horizontal não diferem estatisticamente entre si pelo teste de Tukey a $5 \%$ de probabilidade.

Fonte: Elaboração dos autores.

Os teores de Si na planta são classificados como baixos quando menores que $17 \mathrm{~g} \mathrm{~kg}^{-1}$, médios de $17 \mathrm{a}$ $34 \mathrm{~g} \mathrm{~kg}^{-1} \mathrm{e}$ altos acima de $34 \mathrm{~g} \mathrm{~kg}^{-1}$ (KORNDÖRFER et al., 1999b). Observa-se no Tabela 3, que o teor de Si mais alto foi encontrado na menor dose da adubação nitrogenada combinada com a dose de

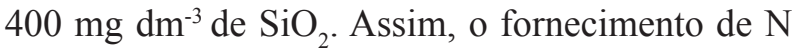
em cobertura ocasionou diminuição nos teores de $\mathrm{Si}$ na planta.

Dentre as praticas de manejo cultural, a adubação nitrogenada exerce forte influencia no $\mathrm{pH}$ do solo (BARBOSA FILHO; FAGERIA; SILVA, 2005) e da rizosfera (SOUSA; MIRANDA; OLIVEIRA, 2007), e de maneira indireta na disponibilidade de silício para as plantas (OLIVEIRA; KORNDÖRFER; PEREIRA, 2007). As formas de Si disponível no solo dependem diretamente da sua concentração na solução do solo e do pH do solo, sendo que quanto mais alcalino, maior o grau de ionização do $\mathrm{H}_{4} \mathrm{SiO}_{4}$ (ILER, 1979)

Plantas quando absorvem $\mathrm{N}$ na forma de amônia $\left(\mathrm{NH}_{4}^{+}\right)$acidificam o $\mathrm{pH}$ rizosferico pela extrusão de $\mathrm{H}^{+}$, enquanto na forma nítrica $\left(\mathrm{NO}_{3}^{-}\right)$promovem aumento pela extrusão de $\mathrm{OH}^{-}$e $\mathrm{HCO}_{3}^{-}$(NYE, 1986). Assim, uma possível explicação para redução do teor de Si na planta com o aumento dos níveis da adubação nitrogenada (Tabela 3) esteja relacionado a manutenção do balanço iônico na plantas alterando $\mathrm{o} \mathrm{pH}$ do solo e da rizosfera em função da fonte nitrogenada empregada (amoniacal).

Oliveira, Korndörfer e Pereira (2007) estudando fontes de nitrogênio e disponibilidade de silício para plantas de arroz, observaram que os tratamentos que receberam $\mathrm{N}$-amônia apresentaram os menores teores de $\mathrm{Si}$ na parte aérea e valores de $\mathrm{pH}$ rizosferico, enquanto os tratamentos que receberam $\mathrm{N}$-nítrico, tanto o teor de Si na parte aérea como o valor de $\mathrm{pH}$ rizosferico forma maiores.

No presente trabalho as estruturas das projeções da parede externa das células da epiderme (Figura 1 e 2) foram semelhantes a ilustrada por Yoshida, Ohnishi e Kitagishi (1962) que descreveram a face externa das células epidérmicas como sendo composta de duas camadas: uma camada mais externa, que corresponde a sílica e cutícula, e uma mais interna que corresponde a sílica-celulose. Segundo os autores, a espessura da camada de sílica varia conforme a disponibilidade de Si.

Nota-se que a medida que houve aumento da doses de nitrogênio e ausência de adubação silicatada (Figuras 1 A, C e E) ocorreu diminuição das projeções na forma de picos na epiderme do limbo foliar das plantas de arroz, tanto a quantidade de picos quanto o tamanho desses, como pode ser observado nas Figuras 1B, 1D e 1F. 
Figura 1. Cortes transversais do limbo da folha bandeira de plantas de arroz (Oryza sativa 1.). Fig A: Aspecto geral do limbo foliar de plantas tratadas com $5 \mathrm{mg}$ de $\mathrm{N}$ e zero de $\mathrm{SiO}_{2}$ (x 400). Fig B: Detalhe de A, mostrando projeções da parede externa da epiderme na face adaxial (x 1000). Fig C: Aspecto geral do limbo foliar de plantas tratadas com $75 \mathrm{mg}$ de $\mathrm{N}$ e zero de $\mathrm{SiO}_{2}$ (x 400). Fig D: Detalhe de C, mostrando projeções da parede externa da epiderme na face adaxial (x 1000). Fig E: Aspecto geral do limbo foliar de plantas tratadas com $150 \mathrm{mg}$ de $\mathrm{N}$ e zero de $\mathrm{SiO}_{2}$ (x 400).Fig F: Detalhe de E, mostrando projeções da parede externa da epiderme na face adaxial (x 1000). Observam-se projeções das células epidérmicas nas adjacências do aparelho estomáticos (seta) (x1000).

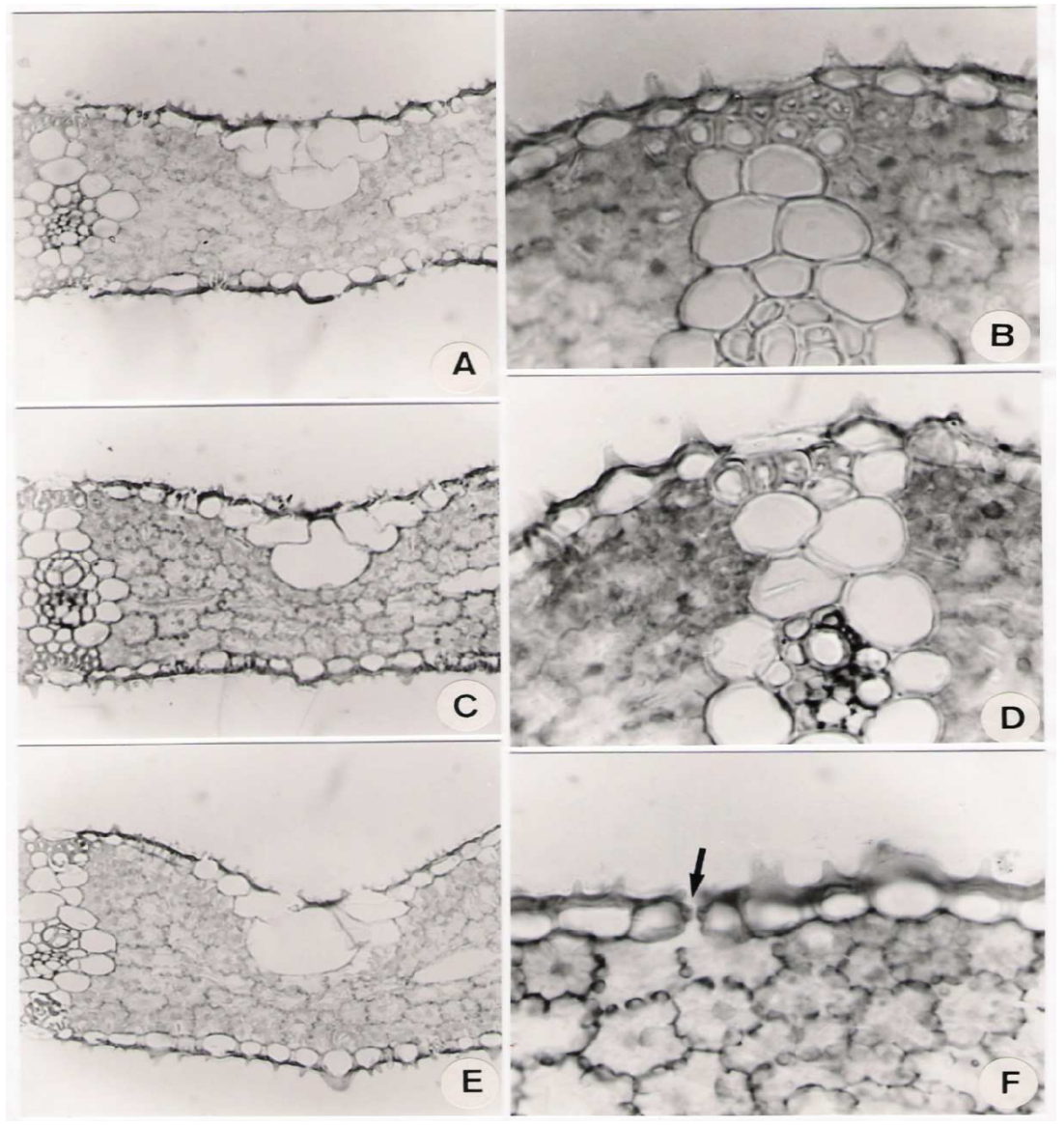

Fonte: Elaboração dos autores.

Observa-se na Figura 2, que quando as plantas de arroz receberam adubação silicatada na dose de 400 $\mathrm{mg} \mathrm{dm}{ }^{-3} \mathrm{de} \mathrm{SiO}_{2}$, os efeitos da adubação nitrogenada nas projeções, tanto em quantidade quanto em tamanho dos picos na epiderme do limbo foliar das plantas de arroz, foram menos pronunciados do que aqueles observados para a mesma dose de nitrogênio e ausência de adubação silicatada (Figura 1). Nota-se ainda na Figura 2, que com adubação silicatada e baixa dose de N (Figura 2 A e B) a presença dos picos de sílica na epiderme do limbo foliar foram mais pronunciados do que observados para mesma dose de silício e $150 \mathrm{mg} \mathrm{dm}^{-3}$ de $\mathrm{N}$ (Figura 2E e 2F). Esses resultados evidenciam os dados apresentados na Tabela 3, onde o aumento da adubação nitrogenada reduziu os teores de Si na

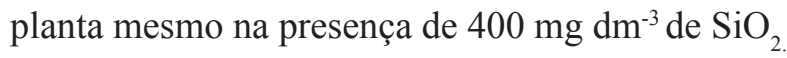


Figura 2. Cortes transversais do limbo da folha bandeira de plantas de arroz (Oryza sativa 1.). Fig A: Aspecto geral do limbo foliar de plantas tratadas com $5 \mathrm{mg}$ de $\mathrm{Ne} 400 \mathrm{mg}$ de $\mathrm{SiO}_{2}$ (x 400). Fig B: Detalhe de A, mostrando projeções da parede externa da epiderme na face adaxial (x 1000). Fig C: Aspecto geral do limbo foliar de plantas tratadas com 75 mg de $\mathrm{N}$ e $400 \mathrm{mg}$ de $\mathrm{SiO}_{2}$ (x 400). Fig D: Detalhe de C, mostrando projeções da parede externa da epiderme na face adaxial (x 1000). Fig E: Aspecto geral do limbo foliar de plantas tratadas com $150 \mathrm{mg}$ de N e $400 \mathrm{mg} \mathrm{de} \mathrm{SiO}_{2}$ (x 400). Fig F: Detalhe de E, mostrando projeções da parede externa da epiderme na face adaxial (x 1000). A seta em F indica o aparelho estomático. As pontas das setas em B e D indicam corpos de sílica esféricos, e em E e F indicam corpos de sílica na forma de agulha ou bastonetes.

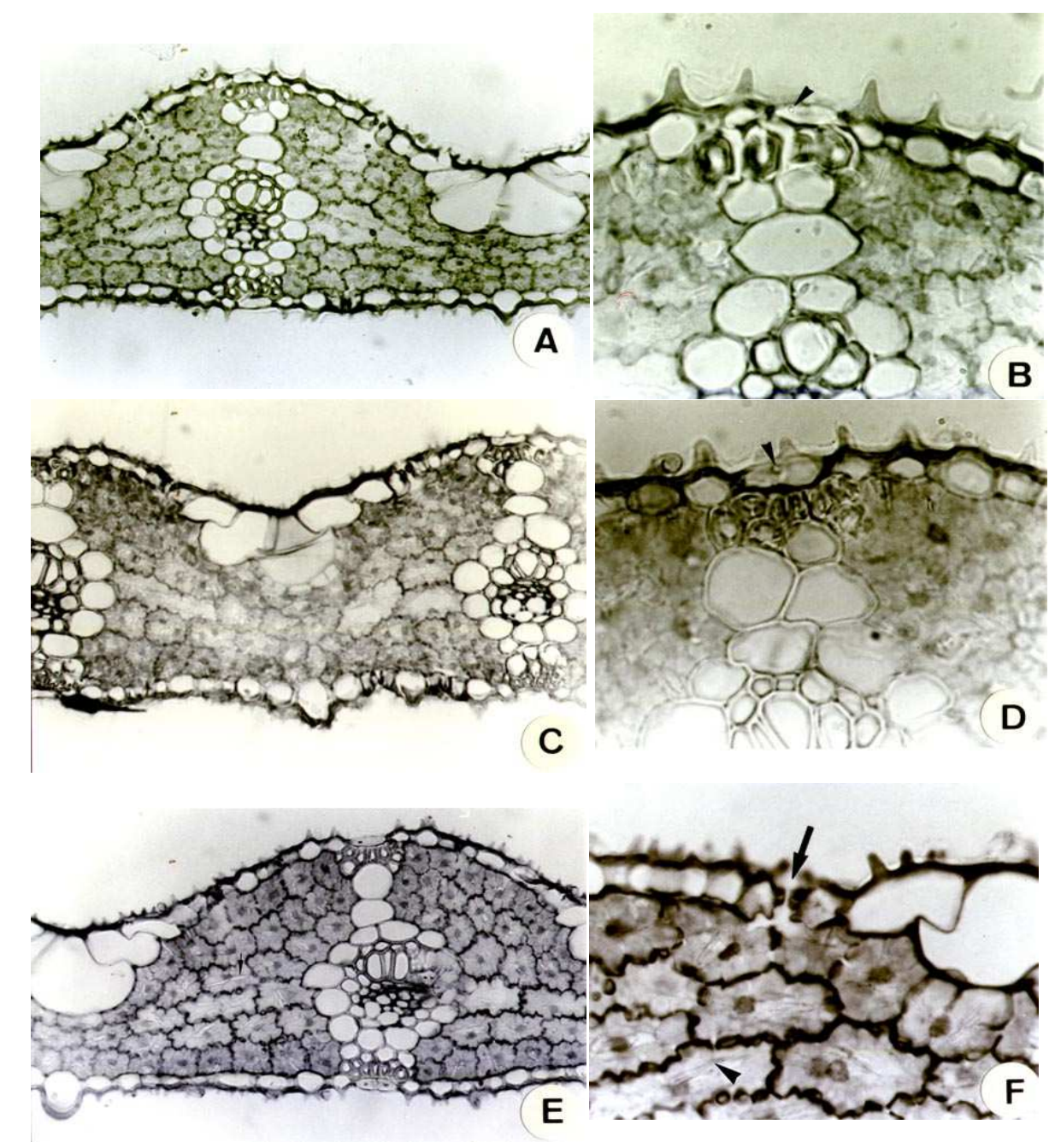

Fonte: Elaboração dos autores.

Redução nos teores de Si em função do aumento dos níveis de adubação nitrogenada foram relatados em arroz, aveia e cana de açúcar (WALLACE, 1989, OLIVEIRA; KORNDÖRFER; PEREIRA, 2007; MEYER, 2005). Segundo Wallace (1989), o nitrogênio diminuiu a concentração de Si nas plantas, sendo a fonte amoniacal ( $\mathrm{N}$-amônio) mais prejudicial que a nítrica para a absorção de silício, o que provavelmente esteja relacionado ao fato de que plantas quando absorvem $\mathrm{N}$ na forma de amônia $\left(\mathrm{NH}_{4}^{+}\right)$acidificam o $\mathrm{pH}$ rizosferico pela extrusão de $\mathrm{H}^{+}$, reduzindo a disponibilidade de silício para as plantas como observado por Oliveira, Korndörfer e Pereira (2007). 


\section{Conclusões}

O incremento da adubação com uréia reduziu o teor de Si na planta de arroz e a deposição de sílica na parede externa das células da epiderme das folhas de arroz.

\section{Referências}

AGARIE, S.; HANAOKA, N.; UENO, O.; MIYAZAKI, A.; KUBOTA, F., AGATA, W.; KAUFMAN, P.B. Effects of silicon on tolerance to water defict and heat stress in rice plants (Oryza sativa L.), monitored by electrolyte leakage. Plant Prodution Science, Tokio, v. 2, n. 1, p. 96103, 1998a.

AGARIE, S.; UCHIDA, H.; AGATA, W.; KUBOTA, F.; KAUFMAN, P.T. Effects of silicon on transpiration and leaf conductance in rice plants (Oryza sativa L.). Plant Prodution Science, Tokio, v. 2, n. 1, p. 89-95, 1998 b.

BARBOSA FILHO, M. P.; FAGERIA, N. K.; SILVA, O. F.de. Fontes, doses e parcelamento da adubação nitrogenada em cobertura para feijoeiro comum irrigado. Ciência e Agrotecnologia, Lavras, v. 29, n. 1, p. 69-76, 2005.

CARMELLO-GUERREIRO, S. M. Técnica de inclusão de material vegetal em historresina. Botucatu: Deartamento de Botânica da UNESP, 1995. 12 p.

DATNOFF, L. E.; ROFRIGUES, F. A.; SEEBOLD, K. W. Silicon and plant disease. In: DATNOFF, L. E.; LEMER, W. H.; HUBER, D. M. (Ed.). Mineral nutrition and plant disease. St Paul: The American Phytopathological Society Press, 2007. cap. 7, p. 233-246.

EMPRESA BRASILEIRA DE PESQUISA AGROPECUÁRIA - EMBRAPA. Centro Nacional de Pesquisa de Solos (Rio de Janeiro, RJ). Sistema brasileiro de classificação de solos. Brasília: EmbrapaSPI, Embrapa-CNPS, 1999. 412 p.

FEDER, N.; O $\square$ BRIEN, T. P. Plant microtechnique: some principles and new methods. American Journal Botanic, Califórnia, v. 55, n. 1, p. 123-42, 1968.

HE, W.; XIN-HUI, S.; CHUANG-DENG, Q.; FUSUO, Z. Immunodetection of silica-binding proteins in rice and outher graminaceous plants. In. SILICON IN AGRICULTURE CONFERES, 3., 2005, Uberlândia, MG. Anais... Uberlândia: Universidade Federal de Uberlândia, 2005. p. 106.

ILER, R. K. The chemestry of silica. New York: Wiley \& Sons, 1979. $1124 \mathrm{p}$.
KORNDÖRFER, G. H.; COELHO, N. M.; SNYDER, G. H.; MIZUTANI, C. T. Avaliação de métodos de extração de silício em solos cultivados com arroz de sequeiro. Revista Brasileira de Ciência do Solo, Viçosa, v. 23, n. 1, p. 101-106, 1999a.

KORNDÖRFER, G. H.; PEREIRA, H. S.; NOLLA, A. Análise de silício: solo, planta e fertilizantes. Universidade Federal de Uberlândia, Uberlândia, 2004. 34 p. (Boletim técnico, 2).

KORNDÖRFER, G. H.; SNYDER, G. H.; ULLOA, M.; PERDOMO, R.; POWELL, C., DEREN, C.; DATNOFF, L. E. Soil and plant silicon calibration for rice production. Florida, 1999b. p. 14-15 (Manuscript prepared for the Rice Council Meeting, Belle Glade).

MALAVOLTA, E.; VITTI. G. S.; OLIVEIRA. S. A. Avaliação do estado nutricional das plantas: princípios e aplicações. 2. ed. Piracicaba: POTAFOS, 1997. 319 p.

MAUAD, M.; CRUSCIOL, C. A. C.; GRASSI FILHO, H. Produção de massa seca e nutrição de cultivares de arroz de terras altas sob condições de déficit hídrico e adubação silicatada. Semina: Ciências Agrárias, Londrina, v. 32, n. 3, p. 939-948, 2011.

MEYER, J. Anoverview of the impact of silicon in allevianting biotic and abiotic stress in sugarcane. In: SILICON IN AGRICULTURE CONFERES, 3., 2005, Uberlândia. Anais... Uberlândia: Universidade Federal de Uberlândia, 2005. p. 62-75.

MOTOMURA, H.; FUJII, T.; SUZUKI, M. Distribution of silicified cells in the leaf blades of pleioblastus chino (Franchet et Savatier) Makino (Bambusoideae). Annals of Botanic, Oxford, v. 85, n. 6, p. 751-757, 2001.

NYE, P. H. Acid-base change in the rhizosphere. Advant Plant Nutrition, Georgia, n. 2, p. 129-153, 1986.

OLIVEIRA, L.A. de; KORNDORFER, G. H.; PEREIRA, A. N. Acumulação de silício em arroz em diferentes condições de $\mathrm{pH}$ de rizosfera. Revista Brasileira de Ciência do Solo, Viçosa, v. 31, n. 4, p. 685-690, 2007.

RAIJ, B. van; CANTARELLA, H.; QUAGGIO, J. A.; FURLANI, A. M. C. Recomendações de adubação e calagem para o estado de São Paulo. 2. ed. Campinas: Instituto Agronômica IAC, 1996. 285 p.

RAIJ, B. van; QUAGGIO, J. A. Métodos de análise de solo para fins de fertilidade. Campinas: Agronômico 1983. 31 p. (Boletim técnico, 81).

RAVEN, J. A. Cycling silicon - the role of accumulation in plants. New Phytologist, Sheffield, v. 2, n. 158, p. 419421, 2003. 
RODRIGUES, F. Á.; BENHAMOU, N.; DATNOFF, L. E.; JONES, J. B.; BÉLANGER, R. R. Ultrastructural and cytochemical aspects of siliconmediated rice blast resistance. Phytopathology, Saint Paul, v. 93, n. 5, p. 535546, 2003.

SANGSTER, A. G.; HODSON, M. J.; TUBB, H. J. Silicon deposition in higher plants. In: DATNOFF, L. E.; SNYDER, G. H.; KORNDORFER, G. H. (Ed.). Silicon in agriculture. Amsterdam, 2001. p. 85-113.

SÁVIO, F. L.; SILVA, G. C. da; TEIXEIRA, I. T.; BORÉM, A. Produção de biomassa e conteúdo de silício em gramíneas forrageira sob diferentes fontes de silicato. Semina: Ciências Agrárias, Londrina, v. 32, n. 1, p. 103110, 2011.

SOUSA, D. M. G.; MIRANDA, L. N.; OLIVEIRA, S. A. Acidez do solo e sua correção. In: NOVAIS, R. F.; ALVARES, V. H.; BARROS, N. F. de; FONTES, R. L. F.; CANTARUTTI, R. B.; NEVES, J. C. L. Fertilidade do solo. Viçosa: [s.n], 2007. cap. 5, p. 205-274.
SOUZA, R. T. V.; KORNDÖRFER, G. H.; WANGEN, R. D. B. Aproveitamento de silício proveniente de escória de siderurgia por cultivares de cana-de-açúcar. Bragantia, Campinas, v. 69, n. 3, p. 669-676, 2010.

TAMAI, K.; MA, J. F. Characterization of silicon uptatake by rice roots. New Phytologist, Sheffield, v. 2, n. 158, p. 419-421, 2003.

WALLACE, A. Relacionships among nitrogen, silicon, and heavy metal uptake by plants. Soil Science, New Brunswick, v. 47, n. 9, p. 457-60, 1989.

WALLACE, A. Participation of silicon in cation-anion balance as a possible mechanism for aluminum and iron tolerance gramineae. Journal Plant Nutrition, Philadelphia, v. 15, n. 9, p. 1345-1351, 1992.

YOSHIDA, S.; OHNISHI, Y.; KITAGISHI, K. Chemical forms, mobility and deposition of silicon in rice plant. Soil Science and Plant Nutrition, Tokyo, v. 1, n. 8, p. 1521, 1962. 
